Asia Pacific Journals

\title{
STUDY OF VARIATION OF COMPRESSION RATIO AND AIR FUEL RATIO ON PERFORMANCE CHARACTERISTICS ON DIRECT INJECTED DIESEL ENGINE
}

\begin{tabular}{|c|c|}
\hline Uday Pratap Singh & Shadwal Singh; Sarang Manar; Shailesh Singh \\
Department of Mechanical Engineering & Department of Mechanical Engineering \\
J.S.S. Academy of Technical Education, Noida & J.S.S. Academy of Technical Education, Noida \\
Noida, India & Noida, India \\
uday@jssaten.ac.in & shadwalnov@ gmail.com \\
\hline
\end{tabular}

\begin{abstract}
Diesel engines are one of the most efficient prime movers commonly available today. They are used to drive automobiles especially heavy vehicles and also a large number of machineries use diesel engine to operate and generate power. Even though diesel engines are in great use there is still a lot of wastage in the fuel utilization in the latter because of inappropriate conditions of operation of the engine.
\end{abstract}

In this study a single cylinder direct injection diesel engine is simulated on the LOTUS ENGINE simulation software version 5.0, the model selected for assigning the input parameters and studying the variations is Kirloskar TV1 model as this model was in the lab setup also for experimentation.

The compression ratio range selected for the analysis is 15 to 22 and Air-Fuel ratio range was taken as 15 to 65 because of this being the general range of operation of diesel engines. The parameters like Brake power, BSFC, Brake torque and BMEP are being assessed at varying rpms in operating range of the selected engine i.e. from 1000-6000 rpm at various combinations of Air-Fuel ratio and compression ratio. Downfall in brake thermal efficiency and increase in exhaust gas temperatures were observed when compression ratio was reduced from 18 to 15 . The brake specific fuel consumption was increased on reducing the compression ratio. Downfall of peak cylinder pressure was observed on reduction of compression ratio and the peak heat release rate was closer to TDC on increasing compression ratios from 15 to higher up till end defined condition. Cumulative study of all observations for all speed ranges at all combinations of airfuel ratio and compression ratio is being done for obtaining a very small narrowed range of both the varying parameters for best possible optimization of performance characteristics at most economical state in terms of fuel.

Keywords- Direct injection, BSFC, BMEP, Brake Power, Brake Torque, Compression Ratio, Air-Fuel Ratio.

\section{INTRODUCTION}

In a developing country like India where major industries mainly rely on fossil fuels for transportation and to fulfil their energy requirements. Also about 1088.4 ton of carbon dioxide is emitted every second into the atmosphere having adverse effects on climate and is main cause for global warming. Globally, about $32 \%$ of carbon dioxide is emitted from transport vehicles and also harmful gases like nitrous oxide and carbon monoxide. This has motivated a vigorous policy debate on alternative pathways for the light duty vehicle transportation sector. Researchers, technologists and automobile manufacturers throughout the world have been putting up their best efforts on the development of engines which would be more efficient than convention ones and should run cleaner. After many studies it is concluded that NOx emission and performance of an engine are related to each other. In order to control NOx formation, the temperature in the combustion chamber should be less then $\mathrm{N}-\mathrm{N}$ dissociation temperature. This can be achieved by using lean mixture $(\phi<0.7)$. This has shown a significant decrement in the NOx emission. But due to lean mixture power output and efficiency of engine has been decrease significantly. Decrement in brake mean effective pressure was also noticed due to low temperature which results in low brake thermal efficiency. [1]

There are various performance parameters of an IC Engine like compression ratio, air fuel ratio, Brake power, Brake specific fuel consumption (BSFC) etc., which affect the efficiency and performance of the engine.

There are various parameters to increase the efficiency of a diesel engine, but most predominant parameters of improving the performance is by:

1) By varying the compression ratio (CR)

2) By varying air fuel $(\mathrm{A} / \mathrm{F})$ ratio.

In this study variation of 3 main output parameters Brake Power, Brake Specific Fuel consumption and Brake thermal Efficiency were found with the variation of $C R$ and $\mathrm{A} / \mathrm{F}$ ratio at different speeds (rpm) using the Lotus Engine software version 5.0. The variation of all the output parameters with input parameters was obtained with the help of software. The various variation trends observed were further validated with the experimental data obtained from VCR engine selected for our project. The engine brake power increases as the compression ratio increases. This is due to the increase in brake torque at high compression ratios. Increase in compression ratio also induces greater turning effect on the cylinder crank. But at constant compression ratio brake torque decreases after achieving a certain maximum point. Heat losses increase with increase in the temperature of the combustion charge i.e. with increase in $\mathrm{CR}$ but after a certain value of $\mathrm{A} / \mathrm{F}$ Ratio it starts decreasing with more A/F Ratio. As the compression ratio increases the $\mathrm{BSFC}$ of the engine decreases due to proper combustion of fuel. [2]. At higher CR proper burning of fuel takes place but subsequently high temperature range is reached with increase of compression ratio, so an optimum value of Compression Ratio is to be determined along with a suitable range of Air-Fuel so that desirable effects of high Compression Ratio can be absorbed with Lean burning so that an 


\section{Asia Pacific Journals}

efficient solution to the engine performance can be determined keeping in mind the pollution effects of the engine by selecting an optimum brake thermal efficiency.

\section{EXPERIMENTAL SETUP}

The experimental setup used was a varying compression ratio diesel engine setup of Kirloskar make with compression ratio varying range from 12-18. The complete specifications of the setup is given below in the Table 1 .

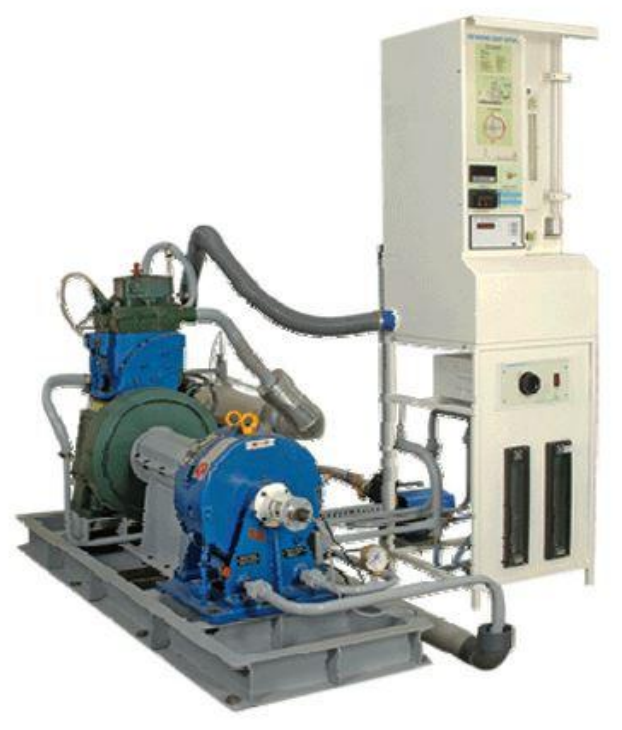

Table 1. Specifications of the VCR Test setup.

The diesel engine test set up comprises of single cylinder, four stroke, and direct injection engine of Kirloskar make. The engine is water cooled with Power rating of $3.5 \mathrm{~kW}$ at 1500 $\mathrm{rpm}$ and the schematic layout can be seen from Fig. 1.The other detailed specifications can be referred from

Table 1 where the engine displacement capacity is $661 \mathrm{cc}$. Engine is also equipped with a Rota meter enabling the engine cooling operating at the range between 40 and $400 \mathrm{~L}$ per hour and enhances calorimeter cooling in the range of 25-250 L per hour. Since the ranges of temperature measurement used in various parts are different, varieties of thermocouples such as RTD, PT 100 and K type thermocouple are employed in the engine for the measurement of engine water temperatures and exhaust temperatures. Pressure measurement for measuring the combustion pressure and fuel inlet pressure are used in the set up where the Piezo electric sensor is used with a low noise cable in the range of 5000 PSI. The Piezo electric sensor senses the pressure and converts them into electrical signals sensor senses the pressure and converts them into electrical signals and the values are displayed as readable by the humans. The control panel contains fuel tank of $15 \mathrm{~L}$ capacity, air box, and manometer and fuel burette. The fuel pump and injector are of denso make with pressure of 220 bar. The fuel flow transmitter is Yokogowa make. The engine is coupled to the eddy current dynamometer of SAJ make which is water cooled for the measurement of load. Strain gauge type load cell is used to measure the load and rotary encoder enables the speed measurement. All the sensors are connected to the data acquisition system. The compression ratio can be changed when the engine is in running condition and specially designed tilting block arrangement is used for the change of CR where the combustion chamber is not altered. [3]. The engine is operated with straight diesel with the properties tabulated in Table 2 which were all tested according to ASTM specifications.

Table 2. Properties of Diesel

\begin{tabular}{|l|l|}
\hline Density at $15 \_C(\mathrm{~kg} / \mathrm{m} 3)$ & 840 \\
Kinematic viscosity at 40_C (mm2/s) & 3.8 \\
Calorific value (MJ/kg) & 42 \\
Flash point (_C) & 45 \\
Carbon residue $(\%)$ & 0.17 \\
Acid value, mg KOH & 0.35 \\
Cetane index & $45-55$ \\
\hline
\end{tabular}

The layout of the virtual engine setup made in Lotus Engine software according to the actual engine setup i.e. Kirloskar TV 1 model used in experimental setup is shown in figure 1 .

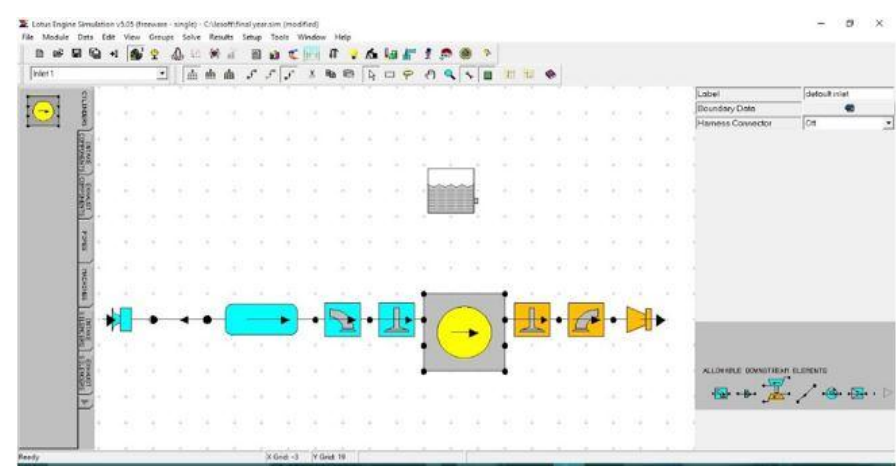

Fig.1. Engine setup build on Lotus Engine version 5.0

\section{Methodology}

As our objective is to optimize the performance characteristics of the Diesel Engine, by analyzing the effect of input parameters on three main output parameters viz. Brake power, Brake specific Fuel Consumption and Brake thermal efficiency.

The engine model selected for the analysis is Kirloskar TV1 model engine and analysis is done on the Lotus Engine Simulation (Freeware single cylinder version) Version 5.0. The engine specifications which are mentioned in the table 1 are fed into the software and a virtual engine model is created. The input parameters and the boundary conditions are further added for each separate case which is required to be analyzed.

For the input parameters we have selected to vary Compression Ratio and Air-Fuel Ratio. The CR is varied from 


\section{Asia Pacific Journals}

15 to 20 and AFR from 15 to 65 individually for each CR. The simulation was further performed and data were tabulated as well as graphs were also obtained. Desired graphs for observing other characteristics was obtained via Microsoft Excel by compiling all the data obtained from Lotus Engine Software.

Finally, after sorting and compiling of data 5 cases of Compression ratio were reduced to 2 cases in which we would get the optimum performance variables, this was done by studying the trend lines of variations of performance parameters at all CRs for the entire Air- Fuel range taken. After the selection of 2 CRs further convergence towards a specific Compression Ratio and a range of Air- Fuel ratio range for best conditions was obtained by simultaneous study of variation of output parameters with their input parameters on surface plots.

\section{RESULT AND DISCUSSION}

By the data analysis we obtained the following graphs:

1. Brake Power vs. Air- Fuel Ratio for all Compression Ratio at complete range of Air- Fuel ratio that we had taken at $1600 \mathrm{rpm}$. The figure 2 below shows the variation obtained.

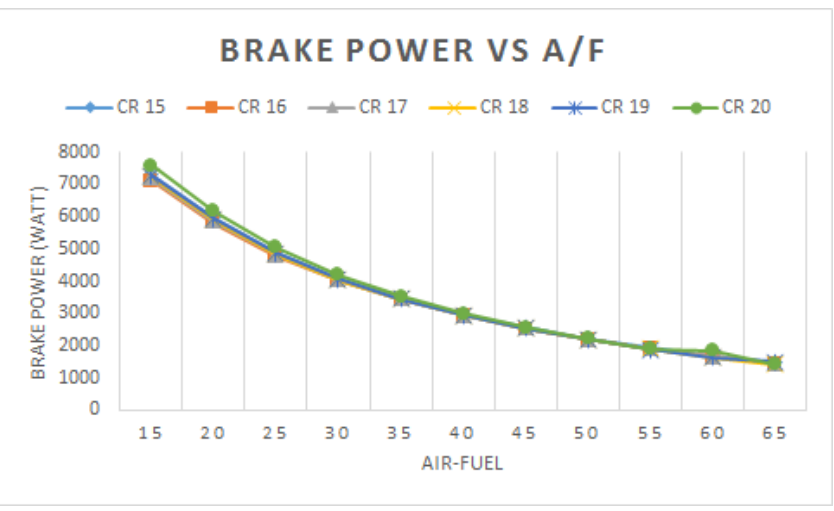

Fig. 2. Brake Power vs. Air-Fuel Ratio for CR 15 to 20

Here we can see that the brake power obtained at CR 20 is maximum and the brake power function is a decreasing with negative slope. We can infer that as the air fuel ratio increases the brake power decreases. The reason for this is that the fuel content at the start is maximum so the heat generated will in turn be more as compared to the latter cases. This will cause generation of more work output at the start. With the increase in compression ratio output also increase hence for same air fuel ratio with higher CR output will be more. But high CR and low AFR will lead to the rise of the engine cylinder temperature by large factors. This fact should also be considered before concluding the result.

2. Brake Thermal Efficiency vs. Air-Fuel Ratio for all Compression Ratio at complete range of Air- Fuel ratio that we had taken at $1600 \mathrm{rpm}$. The figure 3 below shows the variation obtained.

\section{BRAKE THERMAL EFF. VS A/F RATIO}

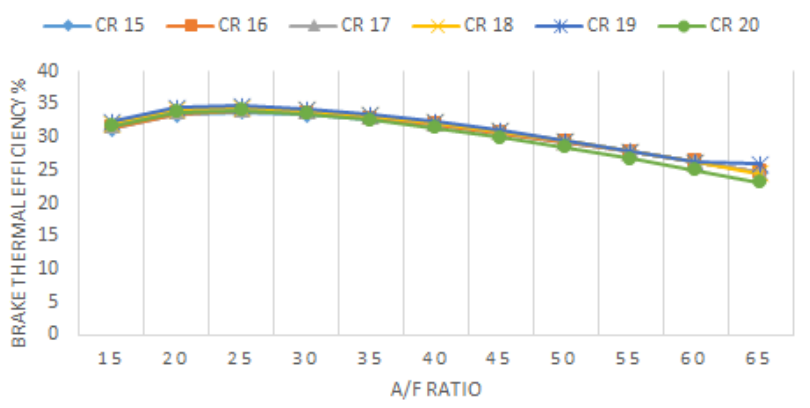

Fig. 3. Brake thermal Efficiency vs. Air- Fuel Ratio for CR 15 to 20

The above graph shows variation of brake thermal efficiency with AFR. Here we can see that the brake thermal efficiency of CR 20 is least among the discussed cases. The reason for lesser brake thermal efficiency can be justified as brake thermal efficiency is defined as ratio of brake power obtained per amount of fuel input and in this case even though the brake power is increasing but the fuel consumption rate increase by larger factor which in turn decreases efficiency. So we can't take CR 20 suitable operation CR due this as well as reason discussed in the above point. But we can see that the BTE of CR 18 and 19 are relatively more and their work output is more. BTE of CR 15, CR 16, CR 17 may be said to be comparable with that of CR 18, CR but their work output is less.

3. Brake specific fuel combustion vs. air fuel ratio for all Compression Ratio at complete range of Air- Fuel ratio that we had taken at $1600 \mathrm{rpm}$. The figure 4 below shows the variation obtained.

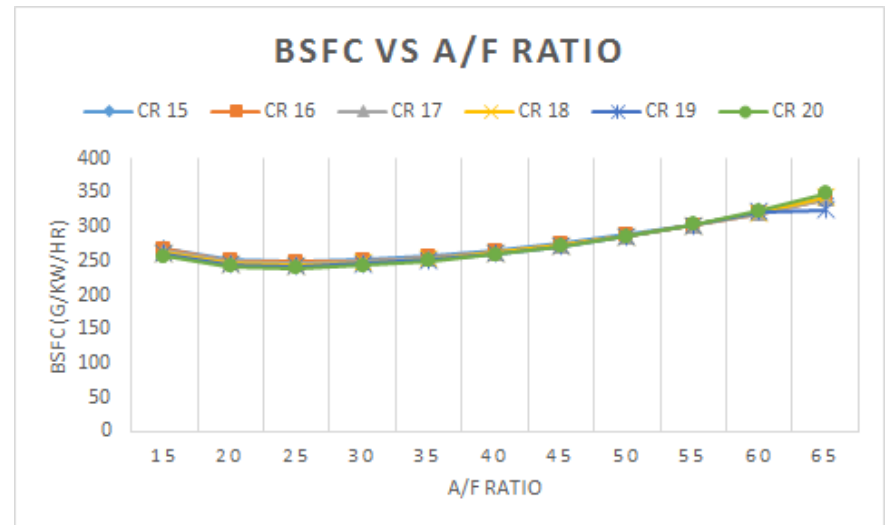

Fig. 4.BSFC vs. Air- Fuel Ratio for CR 15 to 20

As mentioned above regarding CR 20 we can see that the even at the start of the curve the BSFC is less but further the rate of increase or slope of bsfc curve is more and it ends at higher point or reaches to the state of maximum fuel consumption. Hence rejection of case CR 20 is justified. The cases of CR 18 and CR 19 can be observed to operate even below that of CR 16. The reason for this can be said as the CR increases the burning conditions of the fuel increases due to optimum 


\section{Asia Pacific Journals}

pressure conditions and hence the bsfc of the engine decreases. This can be shown as in case of CR 19 as the slope of curve decreases drastically decrease hence can be said it is a suitable operating CR.

4. For checking the dependence of BSFC on Brake power graph was obtained between them for CR 15 to 20 . The trend is shown in Figure 5 below.

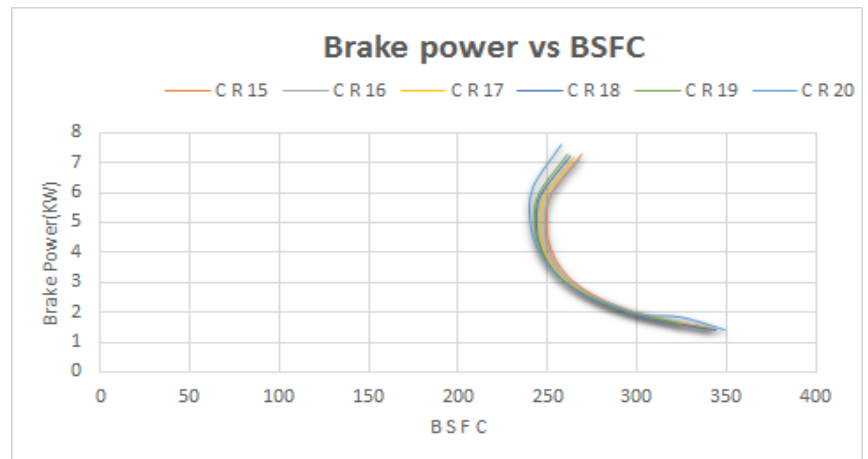

Fig.5. Brake power vs. BSFC for CR 15 to 20

The above graph between Brake power and BSFC shows that the consumption of fuel decrease with the increase in $\mathrm{CR}$, but the decrease is subsequently followed by rise in fuel consumption after falling down to a minimum BSFC lowest in case of CR 20 which is around 6kw brake power.

5. For checking the dependence of Brake Thermal Efficiency on Brake power graph was obtained between them for CR 15 to 20 . The trend is shown in Figure 6 below.

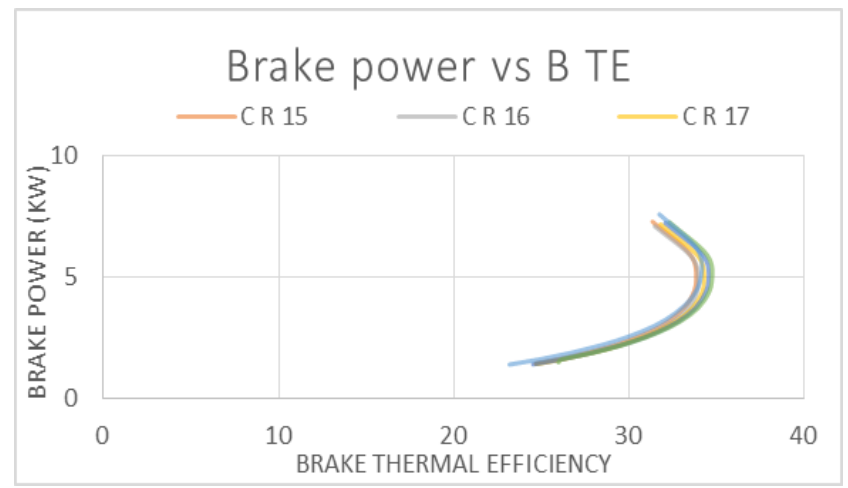

Fig.6. Brake power vs. Brake thermal efficiency for CR 15 to 20

The above graph clearly depicts that after around $6 \mathrm{~kW}$ of Brake power, BTE decreases, CR 19 BTE curve is having a better trend than CR 20 so clearly because of high temperature generated in combustion chamber due to high compression ratio CR 20 is rejected.

From the trends observed in the graphs above and through the data obtained from the VCR Engine we can see that the CR 18 and CR 19 have the best optimum trend of Brake power without compromising the Brake thermal efficiency. Also according to various studies of Diesel Engine for CR 18 and CR 19 we can conclude that for quite a long range of Air- Fuel these CR help in attaining best possible performance. [3] So, for sorting out an exact range of Air- Fuel ratio for a Compression Ratio to get the best optimized performance in terms of all the three parameters viz. Brake power, BSFC, Brake Thermal Efficiency 3-D graphs were obtained with the help of experimental data for the respective CRs on Minitab Version 17.1. These graphs were plotted between an output parameter and its dependent input parameters, depending on the weightage of each input parameters on the taken output parameter slope varied differently on the surface plot enabling to select a region of the more dependent input variable in which the graph was in best optimum possible solution region. Following are the surface plots for CR 18 and CR 19 respectively.

Surface Plot of Brake power vs BSFC, A/F Ratio

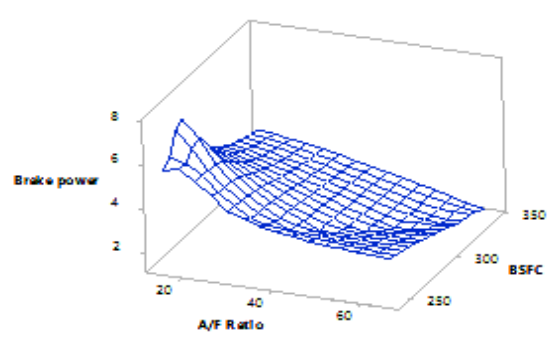

Fig.7.1. CR18 surface plot 1

Surface Plot of Brake thermal effi. vs Brake power, A/F Ratio

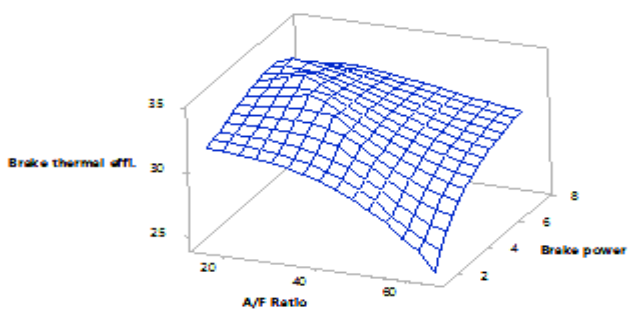

Fig.7.2. CR18 surface plot 2

Through the first surface plot obtained for CR18 we observed that Brake power varies more dramatically with Air- Fuel ratio as compared to BSFC so the main performance of brake power depended more on Air- Fuel ratio at input similarly in second surface plot for CR 18 we observed a similar trend with Brake thermal efficiency, which embarked upon defining a range of Air- Fuel ratio for optimizing the output parameters because with its variation the output parameters showed great variations. From both the surface plots a common region of Air- Fuel ratio in which Brake 


\section{Asia Pacific Journals}

power and Brake thermal efficiency were at its optimum best and at low BSFC was in 25 to 40 range.

Surface Plot of Brake power vs BSFC, AVF Ratio

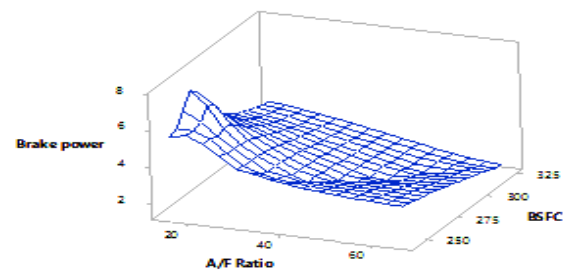

Fig.8.1. CR 19 surface plot 1

Surface Plot of Brake thermal effi. vs Brake power, A/F Ratio

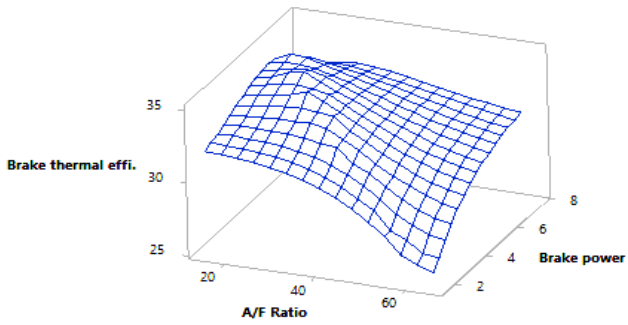

Fig.8.2. CR 19 surface plot 2

Through the surface plots obtained for CR19 we observed that Brake power and Brake thermal efficiency had a similar variation as in case of CR 18 just that the Brake thermal efficiency is fractionally better than in case of CR 18 up till Air- Fuel ratio 50-55 and Brake power is also more compared to CR 18.

\section{CONCLUSIONS}

* Higher compression ratio's generally beyond 19 are not efficient even though the brake power is higher because the rate of increase of BSFC is very high at increasing CRs.

* The NOx emission increases with increase in temperature inside the combustion chamber therefore the thermal conditions of the engine need to be observed so CRs beyond 19 are not suitable as they lead to temperature rise beyond desirable value.

* CRs such as 15, 16 and 17 are not suitable because brake power is less as well as efficiency is less.

* Based on the convergence of the graphs shown above and mathematical optimization of the 3-D equations in Minitab software it was concluded that the
Compression Ratio 19 and Air- Fuel ratio range 2540 was the best optimum combinations of input conditions for the efficient working of the diesel engine in terms of optimum Brake power at economical fuel consumption also at best possible Brake thermal efficiency for preventing loss of heat and its harmful effects in air pollution.

* The main purpose for analyzing the range of AFR is that in direct injection systems the electronic injectors are used and by measuring the quantity of intake air (using MAF sensors) the actual air fuel ratio can be monitored and engine can be made to operate on that range.

\section{ABBREVIATIONS}

\section{BSFC- Brake Specific Fuel Consumption \\ BMEP- Brake Mean Effective Pressure \\ BTE- Brake Thermal Efficiency}

\section{REFERENCES}

[1] Vijay Kumar Attri, Vijay Kumar Sharma, "Effect of Compression Ratio on Performance and Emissions of Diesel on a single Cylinder 4-stroke VCR Engine". IJETAE [ISSN 2250-2459], Volume 5, April 2015

[2] S Gavudhama Karunanidhi, Melvinraj C R, Sarath Das ,K P, G Subba Rao,"CFD Studies of Combustion in Diesel Engine.'International Journal of Engineering Research and Applications (IJERA),ISSN: 22489622,Vol. 3, Issue 4, JulAug 2013, pp.827-830.

[3] V Hariram, R. Vagesh Shangar, "Influence of Compression Ratio on Combustion and Performance Characteristics of Direct Injection Compression Ignition Engines.” Alexandria Engineering Journal(2015) 54,807-814

[4] A.Hatziapostolou, G.Raptis, "CFD Modeling if InCylinder flow in a Variable Compression Spark-Ignited Engine"Proc. of the 9th WSEAS Int. Conf. on Mathematical and Computational Methods in Science and Engineering, Trinidad and Tobago, November 5-7, 2007.

[5] Shahrir Abdullah, Wendy HardyonoKurniawan and AzhariShamsudeen, "Numerical Analysis of the Combustion Process in aCompressed Natural Gas Direct Injection Engine",Journal of Applied Fluid Mechanics, Vol. 1, No. 2, pp. 65-86, 2008.ISSN 1735-3645.

[6] Wendy HardyonoKurniawan, Sharir Abdulla and AzhariShamsudeen, "A Computational Fluid Dynamics Study of Cold Flow Analysis For Mixture Preperation In a Motored Four-Stroke Direct Injection Engine"Journal of Applied Sciences 7 (19): 2710-2724, 2007. ISSN 18125654. 1

[7] T.Morauszki, P.Mandli,Z.Horvath and M.R.Dreyer, "Simulation of Fluid Flow".

[8] H. Raheman, S.V. Ghadge (2008), "Performance of diesel engine with biodiesel at varying compression ratio and injection timing", Fuel 87, 2659-2666.

[9] Y. B. Mathur, M.P. Poonia, A.S. Jethoo, R. Singh (2012), “Optimization of Compression Ratio of Diesel Fueled Variable Compression Ratio Engine", IJEE, 99-101.

[10] M.K. Duraisamy, T. Balusamy \& T. Senthilkumar (2012), "Effect of compression ratio on CI engine fueled with methyl ester of Thevetia Peruviana Seed Oil", APRN Journal of Engineering and Applied Sciences, 229-234.

[11] S. Jindal, B.P. Nandwana, N.S. Rathore, V. Vashistha (2010), "Experimental investigation of the effect of compression ratio and injection pressure in a direct injection diesel engine running on Jetropha Methyl Ester", Applied Thermal Engineering, 442-448.

[12] K. Murlidharan, D. Vasudevan (2011), "Performance, emission and combustion characteristics of variable compression ratio engine using 


\section{Asia Pacific Journals}

methyl esters of waste cooking oil and diesel blends", Applied Energy 88, 3959-3968.

[13] O.Laguitton, C. Crua, T. Cowell, M.R. Heikal, M.R. Gold (2007), "The effect of compression ratio on exhaust emissions from a PCCI diesel engine", Energy Conservation and Management 48, 2918-2924.

[14] Nilesh Mohite (2012), "Study of performance characteristics of variable compression ratio diesel engine using ethanol blends with diesel", International Journal of Engineering Science \&Technology, Vol 4, no.6, $2784-2794$.

[15] A.S. Ramadhas, C. Muraleedharan, S. Jayaraj (2005), "Performance and emission evaluation of diesel engine fueled with methyl esters of rubber seed oil“, Renewable Energy, 1789-1800.

[16] K. Marlidharan, D. Vasudevan, K.N. Sheeba (2011), "Performance, emission and combustion characteristics of biodiesel fueled variable compression ratio engine", Energy, 5385-5393.

[17] Biplab K. Debnath, Niranjan Sahoo, Ujjwal K. Saha (2013), "Thermodynamic analysis of variable compression ratio diesel engine running with palm oil methyl ester", Energy Management,147-154. 